\title{
Allozyme segregation and inter-cytotype reproductive barriers in the polyploid complex Centaurea jacea
}

\author{
OLIVIER J. HARDY*†§, MARC DE LOOSE $\$$, XAVIER VEKEMANS $\dagger$ \\ \& PIERRE MEERTS $\dagger$ \\ $\dagger$ Laboratoire de Génétique et Ecologie Végétales, Université Libre de Bruxelles, Chaussée de Wavre 1850, B-1160 \\ Bruxelles, Belgium, $\ddagger$ Departement Plantengenetica en -veredeling, Centrum Landbouwkundig Onderzoek, \\ Ministerie van Middenstand en Landbouw, Caritastraat 21, B-9090 Melle, Belgium and §elgian National \\ Fund for Scientific Research (F.N.R.S.)
}

\begin{abstract}
In eastern Belgium, diploid and tetraploid knapweeds (Centaurea jacea L. s. l.) show a parapatric distribution with a contact zone. To compare the success of inter- and intra-cytotype crosses, and to investigate the pattern of allozyme segregation, controlled crosses involving plants from this contact zone were performed. Polysomic inheritance at two loci was observed in tetraploids, suggesting an autopolyploid origin. Two crosses allowed the detection of double reduction events in tetraploids at one locus, but no such event was detected among the 217 progenies. Null alleles were detected in tetraploids at two loci. Both cytotypes were highly self-incompatible. Inter-cytotype crosses were much less successful than intra-cytotype crosses in terms of seed set (five-fold reduction) and germination rates (three-fold reduction), suggesting a 'triploid block' effect. Progenies from intercytotype crosses most often had the maternal cytotype and resulted from selfing or pollen contamination. However, six triploids were detected. The significance of these results for the understanding of the geographical distribution of the cytotypes and inter-cytotype gene flow is discussed.
\end{abstract}

Keywords: Centaurea, controlled cross, hybridization, null allele, polyploidy, tetrasomic inheritance.

\section{Introduction}

Contact zones between different cytotypes of a polyploid complex are of considerable interest for studying the dynamics of the interactions between cytotypes, in particular their reproductive isolation (Thompson \& Lumaret, 1992; Petit et al., 1999). Such a contact zone between diploid and tetraploid cytotypes was recently described in the Belgian Ardennes for Centaurea jacea L. sensu lato (Asteraceae), a perennial herb distributed throughout Europe (Hardy et al., 2000). In this contact zone, the two cytotypes are well differentiated genetically and morphologically, and they have broad-scale parapatric distributions, although a few mixed populations occur. As the flowering periods of diploids and tetraploids overlap widely, there is potentially much opportunity for inter-cytotype pollination and hybridization, especially within the mixed populations. This

*Correspondence and present address: Laboratoire de Génétique et Ecologie Végétales, Université Libre de Bruxelles, Chaussée de Wavre 1850, B-1160 Bruxelles, Belgium. E-mail: ohardy@ulb.ac.be raises two issues. First, could inter-cytotype pollination cause the parapatric distribution of the cytotypes through the phenomenon of minority cytotype exclusion? Indeed, if inter-cytotype pollination results in inviable or sterile triploids, the minority cytotype suffers more and eventually disappears (Levin, 1975). For this process to be potentially active, inter-cytotype pollination must therefore lower seed set or result in infertile progeny (Husband, 2000). Secondly, does gene flow occur between diploids and tetraploids? It is suspected that gene flow must occur between cytotypes because diploid and tetraploid populations from Western Europe show correlated spatial patterns of allele frequencies (Hardy \& Vekemans, 2001). However, in a survey of three mixed populations, no triploids were found among 420 individuals (Hardy, 2000). To investigate these issues, crossing experiments involving plants of different cytotypes from a contact zone are needed.

The origin of polyploidy in $C$. jacea has been somewhat controversial. Based on chromosome configuration 
at meiosis, Gardou (1972) inferred an allopolyploid origin because quadrivalents were observed in colchicine-induced artificial autotetraploids, but not in natural tetraploids. More recent data on patterns of allozyme variation and allozyme segregation, however, support a tetrasomic mode of inheritance and thus autopolyploidy (Sommer, 1990; Hardy et al., 2000). Additional data on the mode of inheritance would therefore be useful. It must be noted that several polyploids showing polysomic inheritance (autopolyploids) present few or no multivalents at meiosis, so that this criterion must be considered with caution (e.g. Soltis \& Soltis, 1993; Qu et al., 1998).

Under tetrasomic inheritance, two opposite modes of allele segregation may occur: chromosome segregation or chromatid segregation. With the second mode, the phenomenon of 'double reduction' appears when portions of two sister chromatids are driven into the same gamete, resulting in an increased proportion of homozygous gametes (Demarly, 1963; Ronfort et al., 1998). Double reduction can occur only if quadrivalents are formed at meiosis, but its rate also depends on the locus under consideration because crossing-over located between the locus and the centromere are required (Demarly, 1963). As double reduction causes heterozygote deficiency, in a similar way to selfing, it is important to check its occurrence in order to avoid misinterpretation of genetic marker data. Ronfort et al. (1998) have shown that double reduction alters the values of $F$-statistics.

In this study, controlled crosses were carried out within and between cytotypes of the $C$. jacea complex and progeny genotypes were examined using allozyme markers. The main objectives were: (1) to assess the success of inter-cytotype crosses relative to intra-cytotype crosses to investigate whether processes such as minority cytotype exclusion or inter-cytotype gene flow are likely to occur; (2) to assess the mode of inheritance of allozymes in tetraploids and check for the occurrence of double reduction. As null alleles were detected in the tetraploids at two enzymatic loci, we also discuss the expected difference of null allele frequencies between tetraploids and diploids.

\section{Materials and methods}

Centaurea jacea L. sensu lato (knapweed) is an insect pollinated, self-incompatible herbaceous perennial distributed widely in Europe and found primarily on grassland and hay-meadow habitats. It is a polyploid complex (diploid: $2 n=22$, tetraploid: $2 n=44$ ) which has received controversial taxonomic treatments. Here, because the complex can be regarded as a single biological species (Hardy et al., 2000; Hardy \& Vekemans,
2001), we use the name Centaurea jacea to refer to the whole complex.

Crosses between plants collected from four populations from the diploid/tetraploid contact zone of the Belgian Ardennes (Hardy et al., 2000) were carried out in an open garden. To make the crosses, pairs of capitula at similar developmental stages were enclosed in paper or nylon bags prior to anthesis. At anthesis, those capitula were brushed gently against each other once a day for three to four consecutive days. Achenes obtained from these crosses were germinated in Petri dishes with distilled water, in a growth chamber.

To protect flowering capitula, nylon mesh bags were preferred over paper bags, because the latter proved to favour fungal attacks and were often damaged by slugs. However, nylon bags were probably not as efficient at preventing external pollen contamination.

Crosses between diploids, between tetraploids, and between diploids and tetraploids were carried out. Since C. jacea is strongly self-incompatible (Gardou, 1972), emasculation was unnecessary. However, to obtain a control, self-pollinations were carried out by manipulating capitula of a given individual in the same way as for cross-pollinations. The average number of filled seeds obtained per capitulum was assessed for each cross and these values were compared between cross types using Mann-Whitney $U$-tests. Moreover, seed germination percentages obtained for each cross type were compared using $\chi^{2}$ tests.

The ploidy level of all crossed plants, as well as of the progenies of inter-cytotype crosses, was determined by flow cytometry, a technique that allows the rapid determination of the DNA content per nucleus. Allozyme markers were used to assess the pattern of allozyme segregation in crosses between tetraploids. They also enabled a check of whether the genotypes of progenies from inter-cytotype crosses and self-pollinations matched the genotypes of their putative parents; hence, agamospermy or pollen contamination could be detected.

Protocols used for allozyme electrophoresis and flow cytometry are described in Hardy et al. (2000). Electrophoretic analyses were run on vertical $8 \%$ polyacrylamide gels. Four polymorphic enzyme systems gave interpretable banding patterns using leaf extracts from both seedlings and adult plants: diaphorase (DIA, E.C. 1.8.1.4), leucine-amino-peptidase (LAP, E.C. 3.4.11.1), phosphoglucomutase (PGM, E.C. 5.4.2.2) and 6-phosphogluconate dehydrogenase (PGD, E.C. 1.1.1.44). PGD has one interpretable locus ( $P g d-2)$, characteristic of a dimeric enzyme with four alleles. The other enzymes are monomeric. LAP has one locus (Lap-1) with 11 alleles present in the diploid/tetraploid contact zone (Hardy et al., 2000). PGM and DIA have two diallelic loci, but 
only one of each (Pgm-2 and Dia-2) was sufficiently reliable under these electrophoretic conditions.

To test the mode of inheritance in tetraploids, plants used for crosses were selected according to their genotypes to discriminate between disomic and tetrasomic inheritance and to detect double reduction events. Therefore, we tried to obtain especially large progeny sizes for crosses between tri- or tetra-allelic individuals (only available at Lap-1 and $P g d-2$ loci) and homozygotes. Indeed, such crosses permit the direct inference of gametic genotypes, enhancing the discrimination power between modes of inheritance. $\chi^{2}$ tests were used to check if observed genotype or phenotype frequencies in the progenies were consistent with expected ratios under tetrasomic inheritance (assuming chromosome segregation) and digenic-disomic inheritance (for which different arrangements of alleles between loci were tested). In those cases where both modes of inheritance were rejected, expected ratios when parental genotypes include null alleles were tested.

\section{Results}

\section{Success of crosses}

The seed sets of crosses between diploids and between tetraploids were similar (average number of seeds produced per capitulum: 11.3 for diploids, 11.6 for tetraploids; Mann-Whitney $U$-test: $P=0.98$ ). Germination percentage was somewhat higher in tetraploids (86\% for diploids, $92 \%$ for tetraploids; $\chi^{2}$ test: $P=0.015$ ) (Table 1).

Very few seeds were obtained by self-pollination (average seed set per capitulum: 0.9), and there was no significant difference between diploids $(0.67)$ and tetraploids (1.0) (Mann-Whitney $U$-test: $P=0.81$ ). The germination percentage $(64 \%)$ was significantly lower than for intra-cytotype crosses $\left(\chi^{2}\right.$ test: $\left.P=0.0003\right)$. Among 19 self-pollinations (six on diploids, 13 on tetraploids), 11 (four on diploids, seven on tetraploids) did not yield any seed (Fig. 1), and only six (two on diploids, four on tetraploids) yielded at least one seed that germinated. Based on enzymatic genotypes of five

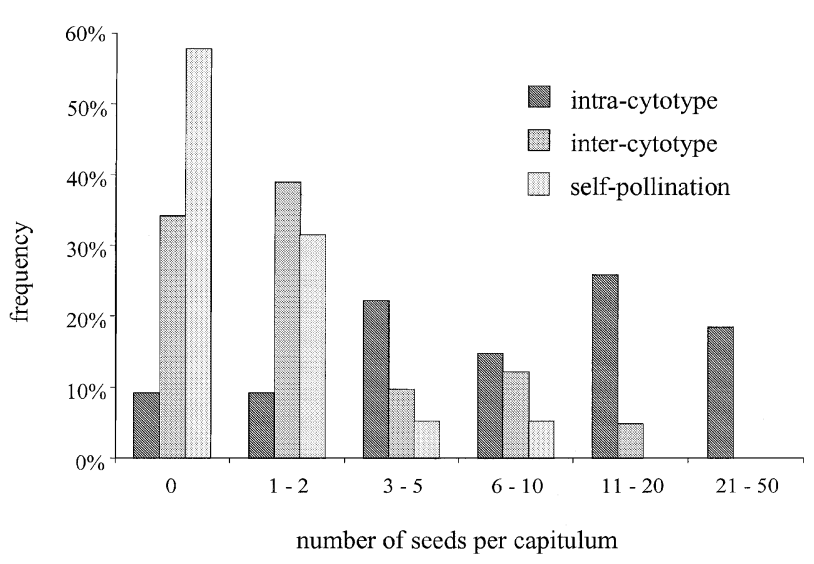

Fig. 1 Frequency distributions of the number of filled seeds per capitulum of Centaurea jacea according to the type of cross.

progenies, no progeny could have resulted from agamospermy and all genotypes were compatible with selfing events, although pollen contamination cannot be ruled out.

Among 41 inter-cytotype crosses, 27 yielded at least one seed (Fig. 1). The average seed set per capitulum (2.2) was five times lower than for intra-cytotype crosses (Mann-Whitney $U$-test: $P<0.001$ ), and higher than for self-pollinations, but the latter difference was not significant (Mann-Whitney $U$-test: $P=0.49$ ). There was no significant difference in seed set according to the maternal cytotype ( 2.28 for a diploid mother, 2.09 for a tetraploid mother; Mann-Whitney $U$-test: $P=0.96)$. The germination percentage $(28 \%)$ was much lower than for intra-cytotype crosses $\left(\chi^{2}\right.$ test: $P<0.001)$ and self-pollinations $\left(\chi^{2}\right.$ test: $\left.P<0.001\right)$. It was not significantly different according to the cytotype of the maternal plant $(34 \%$ with a diploid mother and $22 \%$ with a tetraploid mother; $\chi^{2}$ test: $P=0.09$ ).

Among the 171 seeds resulting from inter-cytotype crosses, 48 germinated. Cytotype could be determined for 39 of these offspring and showed that there were 29 diploids, six triploids and four tetraploids (Table 2). Twenty-six diploids were obtained on a diploid mother.

Table 1 Success of different types of crosses in Centaurea jacea. Values followed by the same letter were not significantly different (see text)

\begin{tabular}{lcccc}
\hline $\begin{array}{l}\text { Type } \\
\text { of cross }\end{array}$ & $\begin{array}{c}\text { No. of crosses } \\
\text { (different parental pairs) }\end{array}$ & $\begin{array}{c}\text { Total no. of filled } \\
\text { seeds obtained }\end{array}$ & $\begin{array}{c}\text { Average no. of } \\
\text { seeds per capitulum }\end{array}$ & $\begin{array}{c}\text { Percentage of } \\
\text { seed germinated }\end{array}$ \\
\hline $2 \mathrm{x} \times 2 \mathrm{x}$ & 19 & 352 & $11.3 \mathrm{a}$ & $86 \% \mathrm{a}$ \\
$4 \mathrm{x} \times 4 \mathrm{x}$ & 35 & 1041 & $11.6 \mathrm{a}$ & $92 \% \mathrm{~b}$ \\
$2 \mathrm{x} \times 4 \mathrm{x}$ & 41 & 171 & $2.2 \mathrm{~b}$ & $28 \% \mathrm{c}$ \\
Self-pollination & 19 & 25 & $0.9 \mathrm{~b}$ & $64 \% \mathrm{~d}$ \\
\hline
\end{tabular}


Table 2 Cytotype and number of viable offspring from inter-ploidy crosses of Centaurea jacea

\begin{tabular}{|c|c|c|c|c|c|c|}
\hline \multirow{2}{*}{$\begin{array}{l}\text { Individuals } \\
\text { crossed } \\
(2 \mathrm{x} \times 4 \mathrm{x})\end{array}$} & \multicolumn{3}{|c|}{$\begin{array}{l}\text { Progeny from } \\
2 \mathrm{x} \text { mother }\end{array}$} & \multicolumn{3}{|c|}{$\begin{array}{l}\text { Progeny from } \\
\text { 4x mother }\end{array}$} \\
\hline & $2 \mathrm{x}$ & $3 x$ & $4 \mathrm{x}$ & $2 \mathrm{x}$ & $3 \mathrm{x}$ & $4 \mathrm{x}$ \\
\hline x136 × x151 & & & & & 1 & \\
\hline $\mathrm{h} 29 \times \mathrm{h} 3$ & & & & 1 & & \\
\hline $\mathrm{x} 143 \times \mathrm{x} 142$ & 3 & & & & & \\
\hline r11 × h68 & 7 & 1 & & & & \\
\hline $\mathrm{x} 123 \times \mathrm{x} 122$ & 1 & & & & & 2 \\
\hline x $108 \times x 127$ & 2 & & & & & 1 \\
\hline $\mathrm{x} 111 \times \mathrm{x} 127$ & 1 & & & & & \\
\hline xf15 × xf9 & 1 & & & 1 & & \\
\hline a9 × xf22 & 1 & & & & & \\
\hline xf15 × a5 & 1 & & & & & \\
\hline xf75 $\times$ xf39 & 3 & & & & & \\
\hline$x f 75 \times x f 9$ & 5 & & & & & \\
\hline $\mathrm{a} 2 \times \mathrm{a} 5$ & 1 & & & 1 & & \\
\hline xf $23 \times$ xf 22 & & & & & 1 & \\
\hline a4 × a5 & & & & & & 1 \\
\hline a9 $\times$ xf 22 & & & & & 2 & \\
\hline $\mathrm{xf} 64 \times \mathrm{f} 22$ & & & & & 1 & \\
\hline Total & 26 & 1 & 0 & 3 & 5 & 4 \\
\hline
\end{tabular}

Among the six triploids, five had a tetraploid mother and one a diploid mother. The four tetraploids had a tetraploid mother.

Enzymatic genotypes of the progeny of inter-cytotype crosses could be scored for 36 individuals with known cytotype (26 diploids, six triploids and four tetraploids). All triploids showed genotypes compatible with the fusion of gametes of their putative parents; one example is shown in Fig. 2. Among the four tetraploids, at least two resulted from pollen contamination. For the other two, one could result from selfing and the other from fertilization by a unreduced pollen grain from the diploid, although pollen contamination cannot be ruled out. Among 23 diploid progenies with a diploid mother, 13 showed genotypes compatible with the selfing of their mother (e.g. diploid progenies in Fig. 2), though pollen contamination cannot be excluded, and 10 must have resulted from pollen contamination. Surprisingly, three diploids were obtained from tetraploid mothers. A tetraploid could yield diploid offspring through the parthenogenetic development of an unfertilized egg cell (Petit et al., 1999). In such a case, fertilization may be necessary for endosperm development, a process called pseudogamy (Richards, 1986). The genotype of one of these diploid progenies was compatible with such a process but this was not true for the two other progenies. Agamospermy could be ruled out in most

\section{Dia-2}

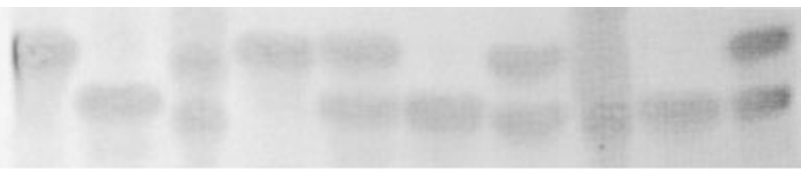

Lap-1
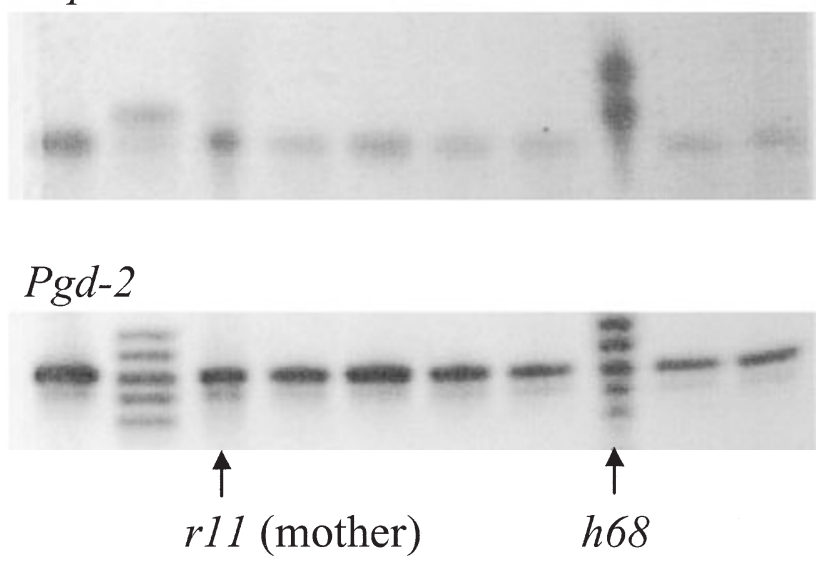

$\begin{array}{llllllllllll}2 \mathrm{x} & 3 \mathrm{x} & 2 \mathrm{x} & 2 \mathrm{x} & 2 \mathrm{x} & 2 \mathrm{x} & 2 \mathrm{x} & 4 \mathrm{x} & 2 \mathrm{x} & 2 \mathrm{x}\end{array}$

Fig. 2 Zymograms of three loci for the parents and progeny of a cross between diploid r11 (female parent) and tetraploid h68 (pollen donor) Centaurea jacea individuals. Progeny cytotypes are indicated below. Genotypes of all diploid progenies are consistent with the selfing of the diploid parent. Genotypes of the triploid progeny are consistent with the fusion of normally reduced gametes from the diploid and tetraploid parents.

of the progenies sharing the same cytotype as their mother.

\section{Patterns of allozyme segregation}

The pattern of allozyme segregation was analysed for three crosses among tetraploids which yielded large enough progeny sizes: 152,64 and 48 for crosses 1 (parents: x145 × x127), $2(\mathrm{~m} 69 \times \mathrm{m} 21)$ and $3(\mathrm{x} 151 \times$ $\mathrm{x} 103$ ), respectively. Genotype interpretation at locus $P g d-2$ was highly reliable due to its dimeric nature (see Fig. 3; Hardy et al., 2000). Hence, this locus was ideal to test for mode of inheritance. Crosses 1 and 2 involved homozygous and tetra-allelic parents at this locus (Fig. 3). For the three crosses, $\chi^{2}$ tests agreed with tetrasomic inheritance, and for crosses 1 and 2, digenicdisomic inheritance could be ruled out because some progeny genotypes could not have been produced (Table 3). In these two crosses, double reduction in a gamete from the tetragenic parent would have produced a genotype different from the ones listed. Hence, tetrasomic inheritance at the $P g d-2$ locus does not show chromatid segregation in $C$. jacea. It is noteworthy that 


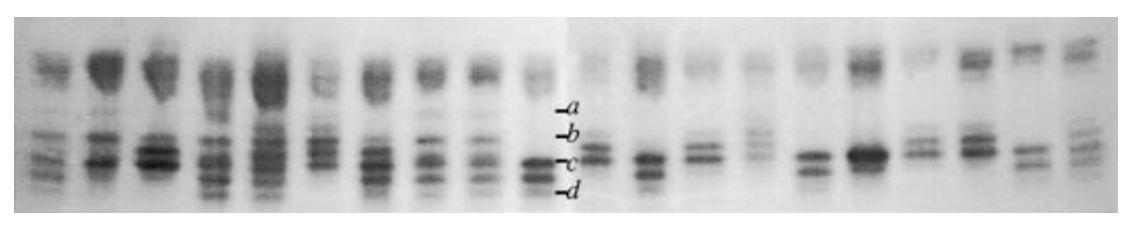

$a d a c \quad b c$ ad $a b c d$ ab bd ad ad $c d$ bc $c d$ bc $a b \quad c d \underline{c c c c} b c \quad b c c d$ bd

Fig. 3 Pgd-2 zymogram for the progeny of cross 1 between tetra-allelic tetraploid (genotype $a b c d$, lane 5) and homozygote tetraploid (genotype $c c c c$, lane 16) individuals of Centaurea jacea. The migration position of each allele $(a, b, c, d)$ is indicated at the centre. The genotype of the gamete coming from the tetra-allelic parent is written below each lane (the progeny genotype is given by the union of this gamete and the homozygous gamete $c c$ ). All six progeny genotypes for this cross are represented on the gel.

\begin{tabular}{lccc}
\hline $\begin{array}{l}\text { Progeny } \\
\text { genotypes }\end{array}$ & $\begin{array}{c}\text { Observed } \\
\text { frequencies }\end{array}$ & $\begin{array}{c}\text { Expected frequencies for two modes of } \\
\text { inheritance and parental genotypes }\end{array}$ \\
\hline Cross 1, abcd $\times c c c c$ & & Tetrasomic & Disomic \\
& & $a b c d \times c c c c$ & $a b, c d \times c c, c c$ \\
$a b c c$ & 29 & 24.67 & 0 \\
$a c c c$ & 16 & 24.67 & 37 \\
$a d c c$ & 24 & 24.67 & 37 \\
$b c c c$ & 31 & 24.67 & 37 \\
$b d c c$ & 19 & 24.67 & 37 \\
$c d c c$ & 29 & 24.67 & 0 \\
& & $\chi^{2}=7.5, \mathrm{~ns}$ & $\mathrm{NA}$ \\
Cross $2, a b c d \times c c c c$ & & Tetrasomic & Disomic \\
& & $a b c d \times c c c c$ & $a b, c d \times c c, c c$ \\
$a b c c$ & 7 & 10 & 0 \\
$a c c c$ & 8 & 10 & 15 \\
$a d c c$ & 12 & 10 & 15 \\
$b c c c$ & 13 & 10 & 15 \\
$b d c c$ & 8 & 10 & 15 \\
$c d c c$ & 12 & $\chi^{2}=3.4, \mathrm{~ns}$ & 0 \\
& & Tetrasomic & DA \\
Cross $3, c c c d \times c c c c$ & & $c c c d \times c c c c$ & $c c, c d \times c c, c c$ \\
& & 22 & 22 \\
$c c c c$ & & 22 & 22 \\
$c c c d$ & 21 & $\chi^{2}=0.9, \mathrm{~ns}$ & $\chi^{2}=0.9, \mathrm{~ns}$ \\
\hline
\end{tabular}

Table $3 \chi^{2}$ tests for mode of inheritance at the dimeric locus $P g d-2$ in Centaurea jacea

$a, b, c, d$ identify alleles.

Tetrasomic inheritance assumes chromosome segregation.

Disomic inheritance assumes a digenic model (genotypes at each locus are separated by a comma).

ns, no significant deviation from the expected values $(P>0.05)$.

NA, some observed progeny genotypes impossible under the model.

only expected genotypes occurred in the progeny, suggesting that external pollen contamination, selfing or agamospermy did not occur in those crosses.

Loci Lap-1, Dia-2 and Pgm-2 being monomeric, genotype interpretation in the tetraploids was not completely reliable regarding allele dosage because different di-allelic (i.e. $a b b b, a a b b, a a a b)$ or tri-allelic (i.e. $a a b c, a b b c, a b c c$ ) genotypes, could not be distinguished with absolute confidence. Hence, the use of the phenotype of zymograms expressed as the presence/ absence of given alleles is more appropriate (Soltis \& Soltis, 1988; Krebs \& Hancock, 1989).

At locus Lap-1 (Fig. 4), crosses 1 and 2 agreed with a hypothesis of tetrasomic inheritance and rejected a hypothesis of digenic-disomic inheritance (Table 4). However, cross 1 gives somewhat striking results as phenotypes $A$ and $A C$ are unexpected a priori in the progeny unless null alleles are assumed to occur in one 


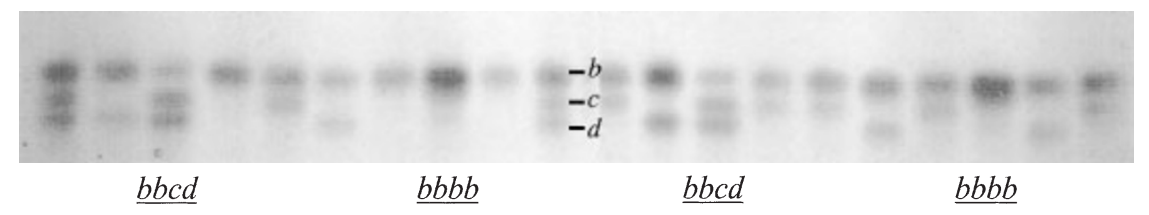

Fig. 4 Lap-1 zymogram for the progeny of cross 2 between tri-allelic tetraploid (genotype bbcd, lanes 3 and 13) and homozygote tetraploid (genotype $b b b b$, lanes 8 and 18) individuals of Centaurea jacea. The migration position of each allele $(b, c, d)$ is indicated at the centre. All four progeny phenotypes for this cross are represented on the gel.

of the parents. Under such a hypothesis (two null alleles present in the parent with phenotype BC), progeny phenotype frequencies are compatible with tetrasomic but not disomic inheritance (Table 4). Alternatively, one could assume that the seven $A$ and $A C$ phenotypes are artefacts due to poor enzyme staining (this is unlikely because staining seemed good for all seedlings). Removing these phenotypes also gives frequencies compatible with tetrasomic inheritance and not with disomic inheritance (Table 4). Selfing or pollen contamination cannot explain the occurrence of the $A$ phenotype because the mother of all progenies had phenotype $B C$, so that allele $b$ and/or $c$ would be present in the progeny if the absence of null alleles is assumed in the mother.

Locus Dia-2 is diallelic and tests on crosses 1 and 2 were not powerful enough to distinguish between tetrasomic and disomic inheritance, both being compatible with progeny phenotypes (Table 4). The same problem arose with locus Pgm-2. However, for the latter, $\chi^{2}$ tests were compatible only if null alleles were assumed to be present in the parents (both under disomic and tetrasomic modes of inheritance, Table 4). Hence, there is evidence that null alleles are present at two enzyme loci.

\section{Discussion}

\section{Tetrasomic inheritance}

Tetrasomic inheritance was proven for at least two loci, confirming previous data suggesting an autopolyploid origin of the tetraploids (Hardy et al., 2000). We also provide evidence that the frequency of double reduction at locus $P g d-2$ must be zero or very close to zero. Lack of double reduction is expected for loci situated close to the centromere and/or if chromosome configuration never involves quadrivalents at meiosis. In C. jacea, Gardou (1972) observed only bivalents at meiosis, suggesting that double reduction might also be absent at the other loci. Most studies testing the pattern of allozyme inheritance in other autopolyploid species also fail to detect double reduction events (e.g. Soltis \& Soltis, 1988; Krebs \& Hancock, 1989; Wolf et al., 1989;
Shore, 1991; but see Quiros, 1982; Martinez-Zapater \& Oliver, 1984).

\section{Null alleles}

Results from two crosses between tetraploids suggest the existence of null alleles at loci Lap-1 and Pgm-2. As allozymes catalyse important cellular functions, a null allele is likely to be deleterious. In allopolyploids, null alleles may occur at high frequency if a homoeologous locus alone assumes gene function. Accordingly, null alleles or complete gene silencing at duplicated loci have been reported in several allopolyploids (e.g. Soltis \& Soltis, 1993, 1999; Leitch \& Bennett, 1997). In contrast, in autopolyploids, deleterious null alleles are always counter-selected even if they are completely recessive, because null allele homozygotes can occur. For a tetrasomic mode of inheritance with chromosome segregation and under panmixia, the frequency of a completely recessive null allele under mutation-selection equilibrium is $(\mu / s)^{1 / 4}$, where $\mu$ is the mutation rate towards the null allele, and $s$ is the selection coefficient against homozygotes at the null allele (Ronfort, 1999). By comparison, the expected frequency for diploids is $(\mu / s)^{1 / 2}$. Mutation rates at allozyme loci for functional alleles are usually estimated at between $10^{-6}$ and $10^{-8}$ mutations per generation, but $80 \%$ to $96 \%$ of mutations might be deleterious (Nei, 1987). Hence, realistic mutation rates towards null alleles might be between $10^{-5}$ and $10^{-7}$ mutations per generation. Assuming a selection coefficient of one (homozygotes at the null allele assumed to be nonviable), the equilibrium frequency of a null allele would be between $1.8 \%$ and $5.6 \%$ for an outcrossing tetraploid (between $0.03 \%$ and $0.3 \%$ for an outcrossing diploid). The probability that a tetraploid individual possesses at least one null allele at a locus would then be between $7 \%$ and $21 \%(0.1 \%$ and $1.3 \%$ for a diploid). These rough estimations show that null alleles might be relatively common in outbred autotetraploids provided that their deleterious effect only appears in homozygotes. Null alleles at allozyme markers have also been reported in other self-incompatible autotetraploids (Lumaret, 1988; Van Dijk \& Van Delden, 1990; Jenczewski et al., 1999). 
Table $4 \chi^{2}$ tests of mode of inheritance at three monomeric loci in Centaurea jacea. Zymograms did not allow inference of allele dosage with absolute confidence, so tests are based on progeny phenotypes instead of genotypes

\begin{tabular}{|c|c|c|c|c|c|}
\hline $\begin{array}{l}\text { Progeny } \\
\text { phenotypes }\end{array}$ & $\begin{array}{l}\text { Observed } \\
\text { frequencies }\end{array}$ & \multicolumn{4}{|c|}{ Expected frequencies for two modes of inheritance and parental genotypes } \\
\hline \multicolumn{6}{|c|}{ Cross 1 , locus Lap-1, parental phenotypes $\mathrm{BC} \times \mathrm{AB}$} \\
\hline & & Tetrasomic & Tetrasomic & Disomic & Disomic \\
\hline & & $b b b c \times a a b b$ & $b c n n \times a a b b$ & $b c, b b \times a b, a b$ & $b n, c n \times a b, a b$ \\
\hline A & 4 & 0 & 4.06 & 0 & 9.12 \\
\hline B & 6 & 12.17 & 12.17 & 18.25 & 18.25 \\
\hline $\mathrm{AB}$ & 72 & 60.83 & 56.78 & 54.75 & 45.63 \\
\hline $\mathrm{AC}$ & 3 & 0 & 8.11 & 0 & 9.12 \\
\hline $\mathrm{BC}$ & 13 & 12.17 & 12.17 & 18.25 & 18.25 \\
\hline \multirow[t]{3}{*}{$\mathrm{ABC}$} & 48 & 60.83 & 52.72 & 54.75 & 45.63 \\
\hline & & NA & $\chi^{2}=10.9, \mathrm{~ns}$ & NA & $\chi^{2}=32.1 * * *$ \\
\hline & & $\left(\chi^{2}=8.0, \mathrm{~ns} \dagger\right)$ & & $\left(\chi^{2}=1.4^{*} \dagger\right)$ & \\
\hline
\end{tabular}

Cross 2, locus Lap-1 parental phenotypes BCD $\times \mathrm{B}$

\section{Tetrasomic}

$b b c d \times b b b b$

$\begin{array}{llc}\text { B } & 10 & 10.67 \\ \text { BC } & 20 & 21.33 \\ \text { BD } & 23 & 21.33 \\ \text { BCD } & 11 & 10.67 \\ & & \chi^{2}=0.3, \mathrm{~ns}\end{array}$

Cross 1, locus Dia-2, parental phenotypes $\mathrm{AB} \times \mathrm{AB}$

$$
\begin{gathered}
\text { Tetrasomic } \\
a a b b \times a a b b \\
4.22 \\
143.5 \\
4.22 \\
\chi^{2}=5.5, \mathrm{~ns}
\end{gathered}
$$

Disomic

$$
\begin{gathered}
b c, b d \times b b, b b \\
15 \\
15 \\
15 \\
15 \\
\chi^{2}=7.6^{* *}
\end{gathered}
$$

\begin{tabular}{|c|c|c|c|c|c|}
\hline & & $\begin{array}{l}\text { Tetrasomic } \\
a a b b \times a a b b\end{array}$ & $\begin{array}{l}\text { Tetrasomic } \\
a a b n \times a b b n\end{array}$ & $\begin{array}{c}\text { Disomic } \\
a b, a b \times a b, a b\end{array}$ & $\begin{array}{c}\text { Disomic } \\
a b, a b \times a b, n n\end{array}$ \\
\hline A & 17 & 4.1 & 12.25 & 9.2 & 18.37 \\
\hline $\mathrm{AB}$ & 118 & 138.8 & 122.5 & 128.6 & 110.25 \\
\hline B & 12 & $\begin{array}{l}4.1 \\
\chi^{2}=59.3 * * *\end{array}$ & $\begin{array}{c}12.25 \\
\chi^{2}=2.0, \mathrm{~ns}\end{array}$ & $\begin{array}{l}9.2 \\
\chi^{2}=8.4^{*}\end{array}$ & $\begin{array}{c}18.37 \\
\chi^{2}=2.9, \mathrm{~ns}\end{array}$ \\
\hline
\end{tabular}

$$
\begin{gathered}
\text { Disomic } \\
a b, a b \times a b, a b \\
9.5 \\
133 \\
9.5 \\
\chi^{2}=2.1, \mathrm{~ns}
\end{gathered}
$$

$$
\begin{gathered}
b b, c d \times b b, b b \\
0 \\
30 \\
30 \\
0 \\
\text { NA }
\end{gathered}
$$

$$
\begin{gathered}
\text { Disomic } \\
a a, b b \times a a, b b \\
0 \\
152 \\
0 \\
\text { NA }
\end{gathered}
$$

$$
\begin{array}{cc}
\text { Tetrasomic } & \text { Disomic } \\
a a b b \times a a b b & a b, a b \times a b, a b \\
1.67 & 3.75 \\
56.67 & 52.5 \\
1.67 & 3.75 \\
\chi^{2}=5.5, \mathrm{~ns} & \chi^{2}=2.1, \mathrm{~ns}
\end{array}
$$

Cross 1, locus Pgm-2, parental phenotypes AB $\times$ AB

$$
\begin{gathered}
\text { Disomic } \\
b n, c n \times a b, a b \\
9.12 \\
18.25 \\
45.63 \\
9.12 \\
18.25 \\
45.63
\end{gathered}
$$$$
2^{2}=1.4^{* \dagger}
$$

$a, b, c, d$ identify alleles to represent genotypes, $n$ represents a null allele. Capital letters represent phenotypes.

Tetrasomic inheritance assumes chromosomal segregation.

Disomic inheritance assumes a digenic model (genotypes at each locus separated by commas).

ns, no significant deviation from the expected frequencies $(P>0.05) ;{ }^{*} P<0.05 ;{ }^{*} P<0.01 ; * * * P<0.001$.

NA, some observed progeny phenotypes impossible under the model.

$\dagger$ Tests with phenotypes A and AC discarded. 


\section{Reproductive isolation - impact on the distribution of the cytotypes}

Our study shows that inter-cytotype pollination in Centaurea jacea yields low seed set and results in low germination percentages. Similar results have been obtained in other autopolyploid complexes (e.g. Lumaret, 1988; Van Dijk \& Van Delden, 1990; Ramsey \& Schemske, 1998). The nearly three-fold reduction in germination percentage may result from triploid seed abortion due to the failure of the endosperm (i.e. triploid block; Ramsey \& Schemske, 1998). The seed set and germination percentage of inter-cytotype crosses are probably somewhat overestimated because a proportion of the offspring actually resulted from pollen contamination or selfing. Pollen contamination is probably due to the use of nylon bags with relatively large mesh size. This problem was detected only in inter-cytotype crosses, suggesting that external pollen formed a small fraction of the pollen load on the stigma, but was much more likely to fertilize ovules when most of the pollen load was not of the 'right' cytotype.

The existence of a post-zygotic reproductive barrier between cytotypes of $C$. jacea and the opportunities for cross-pollination in the contact zone in the Belgian Ardennes (Hardy et al., 2000) suggest that minority cytotype exclusion might be at work. This phenomenon, which corresponds to a frequency-dependent fitness, and was recently demonstrated experimentally (Husband, 2000), could well explain the parapatric distribution of diploid and tetraploid populations of $C$. jacea in the Belgian Ardennes (Hardy et al., 2000), though ecological differentiation between cytotypes might also be involved (Thompson \& Lumaret, 1992; Petit et al., 1997, 1999).

Selfing might be selected within diploid-tetraploid contact zones in response to the phenomenon of minority cytotype exclusion (Levin, 1975; Petit et al., 1997, 1999). It may also be facilitated in autotetraploids because they are expected to suffer less inbreeding depression than diploids (Husband \& Schemske, 1997; Ronfort, 1999). The self-pollination experiments conducted here yielded a few seeds, suggesting that selfing events might have occurred, although pollen contamination may also account for this result. Selfing events were not detected in crossing experiments between tetraploids but they occurred in crossing experiments between diploid and tetraploid. Hence, selfing might occur exceptionally when no pollen of the proper cytotype is available. In agreement, Hardy \& Vekemans (2001) did not detect inbreeding caused by selfing within diploid and tetraploid populations of $C$. jacea in the Belgian Ardennes. Therefore, contrary to other polyploid complexes (Levin, 1983), mainly of allopolyploid origin, polyploidization has not resulted in the loss of the self-incompatibility system in $C$. jacea.

Agamospermy could also help avoiding minority cytotype exclusion in diploid-tetraploid contact zones, and Gardou (1972) suggested that it can occur in C. jacea. However, in the crosses conducted here, agamospermy could be rejected with absolute confidence because of the genetic markers used.

\section{Reproductive isolation - impact on gene flow between cytotypes}

Inter-ploidy crosses have yielded six triploids, indicating that the inter-cytotype reproductive barrier is not complete. For equal numbers of reciprocal diploidtetraploid crosses, five triploids were obtained from a tetraploid mother whereas only one was obtained from a diploid mother. This asymmetry is often observed in autopolyploid complexes (e.g. Bretagnolle \& Thompson, 1995; Ramsey \& Schemske, 1998) and might result from the maternal:paternal genome ratio of the endosperm. Indeed, the latter should be $2: 1$ for normal endosperm development, whereas 1:1 and 4:1 ratios are expected in $4 \mathrm{x} \times 2 \mathrm{x}$ and $2 \mathrm{x} \times 4 \mathrm{x}$ crosses, respectively. However, a 2:1 ratio can be achieved in $4 \mathrm{x} \times 2 \mathrm{x}$ crosses if the maternal polar nuclei leading to the endosperm fail to fuse (Van Dijk \& Van Delden, 1990).

Triploid production in inter-ploidy crosses does not prove that gene flow occurs between cytotypes since it is not known whether triploids can successfully back-cross with diploids or tetraploids. Until now, only two of the six triploids have flowered; they had aborted anthers but, when allowed to be naturally pollinated by nearby diploid and tetraploid individuals, they yielded approximately 30 filled seeds, among which two germinated but only one survived (the chromosome number of the latter has not yet been determined; Vanderhoeven and Hardy, unpublished). Inter-cytotype gene flow may also occur through unreduced gametes from diploids. Apparently, none of the diploids used in these crosses produced such gametes at high frequency, although previous investigations suggest that diploid C. jacea may indeed produce unreduced gametes (Gardou, 1972). Another pathway of inter-cytotype gene flow could be the production of diploid progeny by tetraploids through the apomictic development of egg cells (Petit et al., 1999); this phenomenon may have occurred for one seedling. However, more polymorphic genetic markers would be necessary to assess unambiguously if this phenomenon actually occurs.

The results presented here show that strong, but not necessarily complete, reproductive isolation occurs between diploid and tetraploid C. jacea. A low level of gene flow between cytotypes of $C$. jacea could explain 
the contrasting patterns of genetic variation observed between small and large spatial scales (Hardy \& Vekemans, 2001). Thus, at the European scale, gene frequencies of diploid and tetraploid populations are spatially correlated and cytotypes are little differentiated. By contrast, at a regional scale and within mixed populations, cytotypes are genetically well differentiated and show no spatial correlation of gene frequencies. This pattern might be explained either by rare successful inter-cytotype crosses, or by rare but recurrent formation of tetraploids from local diploids (Hardy \& Vekemans, 2001). Although the present results do not elucidate the actual pathways of gene flow between diploid and tetraploid C. jacea, they confirm that such gene flow occurs at a very low rate.

\section{Acknowledgements}

This work was supported by grant no. 2.4512.97 from the Belgian National Fund for Scientific Research (F.N.R.S.), where Olivier Hardy is a research assistant. We thank Arnaud Cames for carrying out part of the crosses and Hilde Carlier for her help in flow cytometry analyses. We also thank J. Ronfort and two anonymous reviewers for their comments on a previous draft of the manuscript.

\section{References}

BRETAGNOLLE, F. AND THOMPSON, J. D. 1995. Gametes with the somatic chromosome number, mechanisms of their formation and role in the evolution of autopolyploid plants. New Phytol., 129, 1-22.

DEMARLy, Y. 1963. Génétique des tétraplo et amélioration des plantes. Annls Amél. Pl., 13, 307-400.

GARDOU, C. 1972. Recherches biosystématiques sur la Section Jacea Cass. et quelques sections voisines du genre Centaurea L. en France et dans les régions limitrophes. Feddes Repertorium, 83, 311-472.

HARDY, O. J. 2000. Structure spatiale de la variation génétique et relations entre cytotypes dans des populations d'un complexe polyplo: Centaurea jacea L. s.l. PhD Thesis, Université Libre de Bruxelles.

HARDy, O. J. AND vekemans, X. 2001. Patterns of allozyme variation in diploid and tetraploid Centaurea jacea at different spatial scales. Evolution, 55, 943-954.

HARDY, O. J., DE VANDERHOEVEN, S., LOOSE, M. AND MEERTS, P. 2000. Ecological, morphological and allozymic differentiation between diploid and tetraploid knapweeds (Centaurea jacea s.1.) in a contact zone of the Belgian Ardennes. New Phytol., 146, 281-290.

HUSBAND, B. C. 2000. Constraints on polyploid evolution: a test of the minority cytotype exclusion principle. Proc. R. Soc. B, 267, 217-223.

HUSBAND, B. C. AND SCHEMSKE, D. W. 1997. The effect of inbreeding in diploid and tetraploid populations of Epilo- bium angustifolium (Onagraceae): implications for the genetic basis of inbreeding depression. Evolution, 51, 737-746.

JENCZEWSKI, E., PROSPERI, J, M. AND RONFORT, J. 1999. Evidence for gene flow between wild and cultivated Medicago sativa (Leguminosae) based on allozyme markers and quantitative traits. Am. J. Bot., 86, 677-687.

KREBS, S. L. AND HANCOCK, J. F. 1989. Tetrasomic inheritance of isozyme markers in the highbush blueberry, Vaccinium corymbosum L. Heredity, 63, 11-18.

LEITCH, I. J. AND BENNETT, M. D. 1997. Polyploidy in angiosperms. Trends Plant Sci., 2, 471-476.

LEVIN, D. A. 1975. Minority cytotype exclusion in local plant populations. Taxon, 24, 35-43.

LEVIN, D. A. 1983. Polyploidy and novelty in flowering plants. Am. Nat., 122, 1-25.

Lumaret, R. 1988. Cytology, genetics, and evolution in the genus Dactylis. Crit. Rev. Plant Sci., 7, 55-91.

MARTINEZ-ZAPATER, J. M. AND OLIVER, J. L. 1984. Genetic analysis of isozyme loci in tetraploid potatoes (Solanum tuberosum L.). Genetics, 108, 669-679.

NEI, M. 1987. Molecular Evolutionary Genetics. Columbia University Press, New York.

PETIT, C., Lesbros, P., GE, X. AND ThOMPSON, J. D. 1997. Variation in flowering phenology and selfing rate across a contact zone between diploid and tetraploid Arrhenatherum elatius (Poaceae). Heredity, 79, 31-40.

PETIT, C., BRETAGNOLLE, F. AND FELBER, F. 1999. Evolutionary consequences of diploid-polyploid hybrid zones in wild species. Trends Ecol. Evol., 14, 306-311.

QU, L., HANCOCK, J. F. AND WHALlON, J. H. 1998. Evolution in an autopolyploid group displaying predominantly bivalent pairing at meiosis: genomic similarity of diploid Vaccinium darrowi and autotetraploid V. corymbosum (Ericaceae). Am. J. Bot., 85, 698-703.

QUIRos, C. F. 1982. Tetrasomic segregation for multiple alleles in alfalfa. Genetics, 101, 117-127.

RAMSEY, J. AND SCHEMSKE, D. W. 1998. Pathways, mechanisms, and rates of polyploid formation in flowering plants. Ann. Rev. Ecol. Syst., 29, 467-501.

Richards, A. J. 1986. Plant Breeding Systems. George Allen \& Unwin, London.

RONFORT, J. 1999. The mutation load under tetrasomic inheritance and its consequences for the evolution of the selfing rate in autotetraploid species. Genet. Res., 73, 31-42.

RONFORT, J., JENCZEWSKI, E, BATAILLON, T. AND ROUSSET, F. 1998. Analysis of population structure in autotetraploid species. Genetics, 150, 921-930.

SHORE, J. S. 1991. Tetrasomic inheritance and isozyme variation in Turnera ulmifolia vars. elegans Urb. intermedia Urb. (Turneraceae). Heredity, 66, 305-312.

SOLTIS, D. E. AND SOLTIS, P. S. 1988. Electrophoretic evidence for tetrasomic segregation in Tolmiea menziesii (Saxifragaceae). Heredity, 60, 375-382.

SOLTIS, D. E. AND SOLTIS, P. S. 1993. Molecular data and the dynamic nature of polyploidy. Crit. Rev. Pl. Sci., 12, 243-273. SOLTIS, D. E. AND SOLTIS, P. S. 1999. Polyploidy: recurrent formation and genome evolution. Trends Ecol. Evol., 14, $348-352$. 
SOMMER, S. 1990. Isozymanalyse zur Ermittlung genetischer Variabilität und mikroevolutiver Prozesse bei Centaurea sect. Jacea (Asteraceae). Dissertation zur Erlangung des Doktorgrades der Naturwissenschaften. Universität Bayreuth, Bayreuth.

THOMPSON, J. D. AND LUMARET, R. 1992. The evolutionary dynamics of polyploid plants: origins, establishment and persistence. Trends Ecol. Evol., 7, 302-307.
VAN DIJK, P. AND VAN DELDEN, w. 1990. Evidence for autotetraploidy in Plantago media and comparisons between natural and artificial cytotypes concerning cell size and fertility. Heredity, 65, 349-357.

WOLF, P. G., SOlTIS, P. S. AND SOLTIS, D. E. 1989. Tetrasomic inheritance and chromosome pairing behaviour in the naturally occurring autotetraploid Heuchera grossulariifolia (Saxifragaceae). Genome, 32, 655-659. 